COLORECTAL CANCER

\title{
Exon $3 \beta$-catenin mutations are specifically associated with colorectal carcinomas in hereditary non-polyposis colorectal cancer syndrome
}

\author{
V Johnson, E Volikos, S E Halford, E T Eftekhar Sadat, S Popat, I Talbot, K Truninger, J Martin, \\ J Jass, R Houlston, W Atkin, I P M Tomlinson, A R J Silver
}

Gut 2005;54:264-267. doi: 10.1136/gut.2004.048132

See end of article for authors' affiliations Correspondence to: Research UK, Colorectal Cancer Unit, St Mark's Hospital, Harrow, HA1 3UJ, UK; andrew.silver@ cancer.org.uk

Revised version received 23 June 2004

Accepted for publication 20 July 2004

\begin{abstract}
Background and aim: Activating $\beta$-catenin mutations in exon 3 have been implicated in colorectal tumorigenesis. Although reports to the contrary exist, it has been suggested that $\beta$-catenin mutations occur more often in microsatellite unstable $(\mathrm{MSI}+)$ colorectal carcinomas, including hereditary non-polyposis colorectal cancer (HNPCC), as a consequence of defective DNA mismatch repair. We have analysed 337 colorectal carcinomas and adenomas, from both sporadic cases and HNPCC families, to provide an accurate assessment of $\beta$-catenin mutation frequency in each tumour type.

Methods: Direct sequencing of exon 3 of $\beta$-catenin.

Results: Mutations were rare in sporadic (1/83, 1.2\%) and HNPCC adenomas (1/37, 2.7\%). Most of the sporadic adenomas analysed $(80 \%)$ were small $(<1 \mathrm{~cm})$, and our data therefore differ from a previous report of a much higher mutation frequency in small adenomas. No oncogenic $\beta$-catenin mutations were identified in $34 \mathrm{MSI}$ and 78 microsatellite stable (MSI-) sporadic colorectal cancers but a raised mutation frequency $(8 / 44,18.2 \%)$ was found in HNPCC cancers; this frequency was significantly higher than that in HNPCC adenomas $(p=0.035)$ and in both MSI- $(p<0.0001)$ and MSI+ $(p=0.008)$ sporadic cancers. Mutations were more common in higher stage (Dukes' stages $C$ and $D)$ cancers $(p=0.001)$.

Conclusion: Exon $3 \beta$-catenin mutations are associated specifically with malignant colorectal tumours in HNPCC; mutations appear not to result directly from deficient mismatch repair. Our data provide evidence that the genetic pathways of sporadic MSI+ and HNPCC cancers may be divergent, and indicate that mutations in the HNPCC pathway of colorectal tumorigenesis may be determined by selection, not simply by hypermutation.
\end{abstract}

$\mathrm{T}$ he $\beta$-catenin protein functions in cell adhesion and as a downstream transcriptional activator in the Wnt signalling pathway. ${ }^{1}$ In the absence of Wnt signal, pathway components glycogen synthase kinase 3-B (GSK3 $\beta$ ), axin, adenomatous polyposis coli (APC), and phosphoprotein phosphatase $2 \mathrm{~A}$ form a complex that binds and phosphorylates $\beta$-catenin, marking the protein for degradation via the ubiquitin-proteosome system. ${ }^{2}{ }^{3}$ Wnts trigger the canonical pathway and GSK3 $\beta$ inhibition results in cytoplasmic accumulation of unphosphorylated $\beta$-catenin. This stabilised protein then translocates into the nucleus where it modulates gene transcription by interacting with the TCF/LEF I family of transcription factors resulting in transcriptional activation of specific target genes, such as c-Myc and cyclin-D1. ${ }^{4}$

APC is a critical component in the destruction of $\beta$-catenin and, in up to $85 \%$ of colorectal tumours, protein truncating mutations of APC occur and correlate with decreased $\beta$ catenin degradation and transcriptionally active target genes. Some tumours without APC mutations have been shown to contain activating $\beta$-catenin mutations that involve missense mutation or, occasionally, deletion of exon 3 serine/threonine residues. ${ }^{5-16}$ These amino acids are normally phosphorylated by GSK3 3 and are essential for targeted degradation of $\beta$ catenin. ${ }^{17} A P C$ and exon $3 \beta$-catenin mutations are mutually exclusive events ${ }^{69}$ and may play similar roles in the initiation and development of colorectal cancer; but the overall frequency of $\beta$-catenin mutations remains unclear. In some studies, up to $50 \%$ of colorectal carcinomas without inactivating APC mutation have been reported to contain $\beta$-catenin mutations in exon 3 whereas almost no such mutations have been found by others. ${ }^{5} 68918$
Interestingly, $\beta$-catenin mutations have been associated with microsatellite unstable (MSI+) sporadic colorectal carcinomas which are associated with loss of functional DNA mismatch repair. ${ }^{11}{ }^{14}$ It has been proposed that the single base substitutions observed in the $\beta$-catenin gene result from defective mismatch repair; but given that MSI+ cancers are typified by excess small insertions and deletions, it can be argued that the base substitutions typically found in $\beta$-catenin are no more likely to occur than alternatives such as frameshift changes in APC..$^{10}{ }^{11}{ }^{14}$ MSI+ cancers are also found in hereditary non-polyposis colorectal cancer (HNPCC), a syndrome characterised by germline mutation and somatic inactivation of mismatch repair genes. One study demonstrated that $8 / 25(32 \%)$ HNPCC colorectal cancers had $\beta$-catenin mutations although several of these were at nonserine/threonine residues and hence of uncertain functional significance. ${ }^{10}$ Furthermore, no comparable set of sporadic tumours or adenomas was analysed in this study and hence comparisons between $\beta$-catenin mutations in HNPCC cancers and sporadic lesions, and in benign versus malignant tumours, could not be made. Some cancers, moreover, were deemed to be from HNPCC cases on family history alone and without supporting molecular data, leaving open the possibility of misclassification. ${ }^{10}$

Few studies have examined whether $\beta$-catenin mutations occur in colorectal adenomas, the precursor lesions for most

Abbreviations: $\mathrm{MSI}+$, microsatellite unstable; $\mathrm{MSI}-$, microsatellite stable; HNPCC, hereditary non-polyposis colorectal cancer; GSK3 $\beta$, glycogen synthase kinase 3-B; APC, adenomatous polyposis coli; PCR, polymerase chain reaction 
colorectal carcinomas. One study found that $\beta$-catenin mutations are more common $(6 / 48 ; 12.5 \%)$ in small sporadic adenomas $(<1 \mathrm{~cm})$ than in large adenomas $(2 / 82,2.4 \%)$ or cancers $(1 / 72 ; 1.4 \%) .{ }^{12}$ These data led to suggestions that $\beta$-catenin mutations might be the initiating event in the development of a subset of sporadic colorectal tumours but that adenomas with $\beta$-catenin mutations might be less likely to progress than those with APC mutations.

In an attempt to resolve these apparently conflicting data, we evaluated the frequency of exon $3 \beta$-catenin mutations using direct sequencing in a large well defined set of benign and malignant colorectal tumours from sporadic cases, from individuals with a family history of colorectal tumours, and from families with HNPCC.

\section{MATERIALS AND METHODS Patients}

A total of 337 colorectal tumours were obtained from an approximately equal proportion of male and female patients with sporadic or familial colorectal tumours. Patient age range at the time of biopsy was 30-77 years. Adenomas were obtained from the UK Flexible Sigmoidoscopy Screening Trial $^{19}$ and classed as sporadic $(n=83$, age range 5564 years) or family history ( $\mathrm{n}=61$, age range $55-64$ years), a positive family history being scored if an individual reported either two first degree relatives with colorectal cancer or one first degree relative and one second degree relative with colorectal cancer. ${ }^{19}$ HNPCC adenomas ( $\mathrm{n}=37$; age range 43-50 years) were obtained from patients attending the St Mark's Hospital Family Cancer Clinic. In all cases, HNPCC was diagnosed using molecular criteria (germline MSH2 or MLH1 mutations, loss of MSH2 protein in a tumour, MSI or loss of MLHl protein in more than one adenoma, or cancer from a family (Lipton et al., unpublished observations)). For adenomas, a range of characteristics, including size, morphology (tubular, tubulovillous, or villous), and stage of dysplasia were covered. Forty four HNPCC cancers were collected. Seventy eight sporadic microsatellite stable (MSI-) cancers and 34 MSI+ cancers were sampled from patients attending for surgery at St Mark's Hospital or other hospitals in the south of England. Cancers were unselected, except that the sample was enriched for MSI+ cancers because these are a rarer group than MSI- lesions. Cancers were obtained from both the proximal and distal colon, and all grades from poor to well differentiated and Dukes' stages A-C were represented as well as tumours which had metastasised to distant sites (D).

\section{DNA extraction and mutation screening}

Tumour cells were microdissected from $4 \mu \mathrm{m}$ thick section of formalin fixed paraffin embedded tissue and DNA extracted by digesting the tissues with PK lysis buffer ( $100 \mathrm{mM}$ Tris$\mathrm{HCl}$ (pH 8.0), $500 \mathrm{mM} \mathrm{KCl}, 0.01 \%$ Tween 20, and $200 \mu \mathrm{g} / \mathrm{ml}$

Table 1 Frequency of pathogenic $\beta$-catenin mutations in the tumour types studied

\begin{tabular}{lll}
\hline Tumour type & No studied & $\begin{array}{l}\boldsymbol{\beta} \text {-catenin mutation } \\
\text { frequency }(\%)\end{array}$ \\
\hline Sporadic adenoma & 83 & $1(1.2)$ \\
Family history adenoma & 61 & $1(1.6)$ \\
HNPCC adenoma & 37 & $1(2.7)$ \\
Sporadic cancer, MSI- & 78 & 0 \\
Sporadic cancer, MSI+ & 34 & 0 \\
HNPCC cancer & 44 & $8(18.2)$ \\
\hline
\end{tabular}

One non-pathogenic mutation was identified in a sporadic adenoma and one non-pathogenic mutation in a sporadic cancer.

$\mathrm{MSI}$, microsatellite unstable; MSI-, microsatellite stable; HNPCC, hereditary non-polyposis colorectal cancer.
Table 2 Details of pathogenic $\beta$-catenin mutations detected

\begin{tabular}{lll}
\hline Tumour type & Mutation $(\mathbf{n})$ & Amino acid change \\
\hline $\begin{array}{l}\text { Sporadic adenoma } \\
\text { Family history }\end{array}$ & $\begin{array}{l}\text { del codon 24-38 (1) } \\
\text { del codon 25-32 (1) }\end{array}$ & $\Delta$ HWQQQQSQSYLSGIHSG \\
HNPCC adenoma & ACC $\rightarrow$ GCC (1) & T41A \\
HNPCC cancer & ACC $\rightarrow$ ATC (1) & T411 \\
HNPCC cancer & ACC $\rightarrow$ GCC (3) & T41A \\
HNPCC cancer & TCT $\rightarrow$ TTT (4) & S45F \\
\hline
\end{tabular}

One non-pathogenic mutation (GGA $\rightarrow$ GTA; G34V) was identified in a sporadic adenoma and one non-pathogenic mutation (ACC $\rightarrow$ GCC; $\mathrm{H} 36 \mathrm{P}$ ) in a sporadic cancer.

HNPCC, hereditary non-polyposis colorectal cancer.

proteinase $\mathrm{K}$ ). Exon 3 of $\beta$-catenin was amplified by polymerase chain reaction (PCR) using primer pair: forward, 5'-GAA CCA GAC AG AAA AGC GGC TG-3' and reverse, 5'-ACT CAT ACA GGA CTT GGG AGG-3' (nucleotides 257278 and 410-390 respectively; GenBank NM001904). Each PCR reaction comprised a $20 \mu \mathrm{l}$ reaction mixture containing 0.5 units of Taq polymerase, $0.25 \mu \mathrm{M}$ of each primer, $0.2 \mu \mathrm{M}$ deoxynucleotide triphosphates, $2.5 \mathrm{mM} \mathrm{MgCl}_{2}$, and $\times 1 \mathrm{PCR}$ buffer containing $100 \mathrm{mM}$ Tris- $\mathrm{HCl}$ ( $\mathrm{pH} 8.0$ ), $500 \mathrm{mM} \mathrm{KCl}$, and $0.01 \%$ Tween-20. Reaction conditions were as follows: $94^{\circ} \mathrm{C}$ for five minutes and then 35 cycles of $94^{\circ} \mathrm{C}$ for one minute, $55^{\circ} \mathrm{C}$ for one minute, $72^{\circ} \mathrm{C}$ for one minute followed by a final extension of $70^{\circ} \mathrm{C}$ for 10 minutes. Products were purified and then sequenced in both directions using Big Dye Terminator Cycle Sequencing kit (Perkin Elmer Applied Biosystems). The sequence reactions were run and analysed on an ABI 3100 Genetic Analyzer (Perkin Elmer Applied Biosystems). Only nucleotide changes verified by repeat amplification and repeat sequencing in both directions were recorded as mutations and only mutations at serine or threonine phosphorylation sites were classed as pathogenic. To identify microsatellite instability (MSI) where necessary, tumour DNA samples were amplified using the mononucleotide BAT-26 marker and the products detected on the ABI 3100 genetic analyser. The BAT-26 marker has been shown to be sufficient to identify MSI+ in a range of HNPCC cancers and sporadic colorectal cancers. ${ }^{20-22}$ Our own data (Lipton et al, unpublished) provide further support for this. We did not screen for APC mutations, owing to well established evidence that pathogenic $\beta$-catenin and APC mutations are mutually exclusive events.

\section{Immunohistochemistry}

Immunohistochemistry was performed on formalin fixed paraffin embedded tumour samples using the avidin-biotin complex protocol. Tumour tissue sections were dried, deparaffinised, and stained with the mouse antihuman monoclonal antibody (E-5) from Santa Cruz Biotechnology (California, USA).

\section{RESULTS}

Sporadic $(n=83)$, family history $(n=61)$, and HNPCC adenomas $(n=37)$ were collected from the proximal $(37 \%)$ and distal $(63 \%)$ colon. One putative pathogenic mutation was detected in a sporadic adenoma, one in a family history adenoma, and one in an HNPCC adenoma (tables 1, 2). The change in the HNPCC adenoma was a typical missense mutation at codon 41 but mutations in the sporadic and family history adenomas were both unusual and involved inframe deletions within the $\mathrm{NH}_{2}$ regulatory domain of $\beta$-catenin (codons 29-48). The mutation in the sporadic adenoma involved deletion of Ser-33. The family history adenoma lost the eight amino acids immediately prior to 
Table 3 Characteristics of hereditary non-polyposis colorectal cancers and frequency of pathogenic $\beta$-catenin mutations

\begin{tabular}{|c|c|c|c|c|c|c|c|c|c|}
\hline & \multicolumn{2}{|l|}{ Site } & \multicolumn{4}{|l|}{ Stage } & \multicolumn{3}{|c|}{ Grade* } \\
\hline & Proximal & Distal & A & B & C & D & Well & Mod & Poor \\
\hline Total & 17 & 18 & 7 & 18 & 9 & 2 & 2 & 28 & 8 \\
\hline No of mutations & 4 & 3 & 1 & 0 & 4 & 2 & 0 & 6 & 1 \\
\hline$\%$ & 23.5 & 16.7 & 14.2 & 0 & 44.4 & 100 & 0 & 21.4 & 12.5 \\
\hline
\end{tabular}

Ser-33, including the serine residue at codon 29; while Ser-29 has not been proven to be a GSK3 $\beta$ phosphorylation target, deletion of multiple amino acids at this site is highly likely to result in conformational changes within the $\mathrm{NH}_{2}$ regulatory domain and, consequently, dysfunction at critical phosphorylation sites such as Ser-33 (tables 1, 2). In addition, one sporadic adenoma harboured a mutation of uncertain functional importance (table 2). Most of the sporadic adenomas $(67 / 83,80.1 \%)$ screened were small $(<1 \mathrm{~cm})$ and the presence of only one mutation involving a serine/ threonine residue $(1 / 67,1.5 \%)$ differed from an earlier report of a mutation frequency of $12.5 \%(6 / 48)$ in such small adenomas. ${ }^{12}$ Overall, the results indicated that exon 3 $\beta$-catenin mutations were rare in colorectal adenomas of any origin.

Next, a panel of sporadic colorectal cancers $(n=112)$ with and without MSI (negative, $\mathrm{n}=78$; positive, $\mathrm{n}=34$ ) was investigated for $\beta$-catenin mutations. Only one somatic mutation was detected in an MSI- cancer. This change, a heterozygous A-to-C transversion mutation H36P (table 2) did not involve a serine or threonine residue and was therefore classed as non-pathogenic.

In contrast with our findings in sporadic cancers and adenomas, we detected eight mutations in a total of 44 HNPCC cancers screened (18.2\%; table 1). All of these mutations were missense changes, causing alteration of threonine at codon $41(n=4)$ or serine at codon $45(n=4)$. The difference in mutation frequency between HNPCC carcinomas and sporadic cancers was highly significant $(\mathrm{p}<0.001$, Fisher's exact test) also when HNPCC cancers were compared separately with MSI- and MSI+ sporadic carcinomas $(\mathrm{p}<0.0001$ and 0.008 , respectively, Fisher's exact test). Furthermore, $\beta$-catenin mutations were more common in cancers than adenomas from HNPCC (8/44 $v$ 1/37; $\mathrm{p}=0.028$, Fisher's exact test). In HNPCC, all pathogenic $\beta$-catenin mutations arose in MSI+ tumours (adenomas or carcinomas); there is therefore no evidence that the mutations occurred before mismatch repair inactivation.

There was no association within the HNPCC cancers between $\beta$-catenin mutation and proximal or distal site ( $p=0.69$, Fisher's exact test) (table 3 ) but interestingly a link between mutation and later Dukes' stage (C and D) was identified $(\mathrm{p}=0.001$; stages $\mathrm{C} / \mathrm{D} v$ stages $\mathrm{A} / \mathrm{B}$; odds ratio 28.8 (95\% confidence interval 2.8-295)). There was no association between cancer grade and mutation frequency $(p=1.0$, Fisher's exact test) (table 3). Overall, our results indicate that $\beta$-catenin mutations are relatively frequent in HNPCC cancers (particularly those staged $C$ or D), significantly less common in adenomas than cancers from HNPCC $(p=0.035$, Fisher's exact test), and are unlikely to be related in a simple fashion to the MSI+ status of the tumour.

Immunohistochemical staining in six of the HNPCC cancers with a $\beta$-catenin mutation showed nuclear and cytoplasmic staining in four samples and localisation of protein in the membrane but not the nuclei or cytoplasm of the two other cancers.

\section{DISCUSSION}

Exon $3 \beta$-catenin mutations have been identified in a number of human tumours, including colorectal cancer. ${ }^{23}$ Most mutations involve missense alteration of serines and threonines in the GSK3 $\beta$ phosphorylation region, resulting in decreased APC associated degradation, raised $\beta$-catenin protein levels, and increased TCF4 transcriptional activation. ${ }^{6}$ In colorectal tumours, various frequencies of $\beta$-catenin mutation have been reported in different tumour types.

We have sequenced exon 3 in 343 colorectal tumours from several different origins. We have shown that $\beta$-catenin mutations are rare in adenomas, including those from HNPCC patients. A large proportion of the adenomas screened $(80 \%)$ were small $(<1 \mathrm{~cm})$ and our data are therefore discordant with an earlier report of an increased $\beta$-catenin mutation frequency in small colorectal adenomas compared with larger adenomas or cancers. ${ }^{12}$ Our results do not support the idea that, compared with APC mutations, $\beta$-catenin mutations provide only a growth advantage sufficient for the development of small adenomas, or that this advantage is too "weak" to cause progression to larger adenomas or cancers.

Our results have indicated a relatively high frequency of pathogenic $\beta$-catenin mutations in HNPCC cancers $(8 / 44$, $18.2 \%)$. A higher frequency $(4 / 11,25 \%)$ of $\beta$-catenin mutations involving serine and threonine residues has been reported in a smaller number of cancers from HNPCC families with a molecular diagnosis; this frequency is not significantly different from our own findings $(p=0.19$, Fisher's exact text) although no adenomas or sporadic cancers were analysed in the previous study. ${ }^{10}$ It appears most likely that, contrary to expectations, $\beta$-catenin mutations do not, in general, initiate tumorigenesis, as APC mutations are thought to do, but instead occur during or after progression of adenoma to carcinoma in HNPCC. In this respect, it was interesting that the majority of our pathogenic mutations were identified in the later Dukes' stage tumours $C$ and $\mathrm{D}$. This suggests that activating $\beta$-catenin mutation may occur relatively late in HNPCC tumour progression thereby influencing survival of tumour cells already harbouring mutations in genes associated with initiation and early tumour progression. We cannot entirely exclude the alternative possibility that HNPCC adenomas with $\beta$-catenin mutations are more likely to progress to cancer although there is no obvious explanation for this. Mutation of $\beta$-catenin does not appear, moreover, to arise as a direct consequence of the mismatch repair deficient status of HNPCC tumours. The $\beta$-catenin mutation spectrum contrasted with mutations in the coding oligonucleotide tracts of genes such as TGFBIIR, $B A X$, and TCF4 which typically occur in both HNPCC and sporadic MSI+ cancers.

The underlying reason for the increased frequency of $\beta$-catenin mutations in HNPCC cancers, but not in sporadic MSI+ cancers, remains unclear. It is likely that $\beta$-catenin mutations are selected in HNPCC cancers but not in sporadic MSI+ cases. Our data provide further evidence that while the genetic pathways of tumorigenesis in HNPCC and sporadic 
MSI+ cancers overlap to a large degree, they can be divergent. It is notable that, unlike HNPCC, sporadic MSI+ cancers generally acquire MSI during the transition from benign tumour to malignancy. ${ }^{24-27}$ We cannot state with certainty whether $\beta$-catenin mutations occur before or after loss of mismatch repair in HNPCC tumorigenesis although our data and the finding of defective mismatch repair in very early adenomas $^{26}$ suggests that the latter is more likely to be correct.

In summary, the data presented here indicate that exon 3 $\beta$-catenin mutations are rare in small $(<1 \mathrm{~cm})$ sporadic adenomas, HNPCC adenomas, and in both MSI positive and negative sporadic colorectal cancer. In contrast, activating mutations occur at a significantly increased frequency in HNPCC cancer but the single base pair substitutions observed might not be related directly to the deficient mismatch repair which is characteristic of this group of familial tumours. Our study indicates that activation of the $\beta$-catenin-TCF signalling pathway is an important factor in the HNPCC pathway of tumorigenesis. Further investigation is necessary to establish the relative importance of changes in $\beta$-catenin, $A P C$, and other Wnt pathway genes in HNPCC cancers, particularly in more advanced disease. It remains possible that genetic changes involving non-Wnt proteins drive tumorigenesis in the early stages of HNPCC.

\section{ACKNOWLEDGEMENTS}

We thank the patients and their doctors. This work was supported by Cancer Research UK.

\section{Authors' affiliations}

V Johnson, E Volikos, W Atkin, J Martin, A R J Silver, Cancer Research UK Colorectal Cancer Unit, St Mark's Hospital, Harrow, UK E T Eftekhar Sadat, I Talbot, Academic Department of Pathology, St Mark's Hospital, Harrow, UK

S E Halford, Molecular and Population Genetics Laboratory, London Research Institute, Cancer Research UK, London, UK

I P M Tomlinson, Cancer Research UK Colorectal Cancer Unit, St Mark's Hospital, Harrow, UK, and Molecular and Population Genetics Laboratory, London Research Institute, Cancer Research UK, London, UK S Popat, R Houlston, Section of Cancer Genetics, Institute of Cancer Research, Sutton, UK

K Truninger, Division of Gastroenterology, Catonal Hospital Aarau, Switzerland

J Jass, Department of Pathology, Duff Medical Building, Montreal, Canada

Conflict of interest: None declared.

\section{REFERENCES}

1 Wong NA, Pignatelli $M$. $\beta$-catenin-a linchpin in colorectal tumorigenesis? Am J Pathol 2002;160:389-401.

2 Aberle $\mathrm{H}$, Baver A, Stappert J, et al. $\beta$-catenin is a target for the ubiquitinproteasome pathway. EMBO J 1997; 16:3797-804.

3 lkeda S, Kishida S, Yamamoto $\mathrm{H}$, et al. Axin, a negative regulator of the Wnt

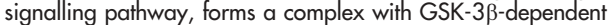
phosphorylation of $\beta$-catenin. EMBO J 1998;17:1371-84.
4 D'Orazio D, Muller PY, Heinimann K, et al. Overexpression of Wnt target genes in adenomas of familial adenomatous polyposis patients. Anticancer Res 2002;22:3409-14.

5 Ilyas $M$, Tomlinson IP, Rowan A, et al. $\beta$-catenin mutations in cell lines established from human colorectal cancers. Proc Natl Acad Sci USA 1997;94:10330-4.

6 Morin PJ, Sparks AB, Korinek $V$, et al. Activation of $\beta$-catenin-TCF signalling in colon cancer by mutations in $\beta$-catenin or APC. Science 1997:275:1787-90.

7 Kitaeva MN, Grogan L, Williams JP, et al. Mutations in $\beta$-catenin are uncommon in colorectal cancer occurring in occasional replication errorpositive tumors. Cancer Res 1997;57:4478-81.

8 Iwao K, Nakamori S, Kameyama M, et al. Activation of the $\beta$-catenin gene by interstitial deletions involving exon 3 in primary colorectal carcinomas without adenomatous polyposis coli mutations. Cancer Res 1998;58:1021-6.

9 Sparks AB, Morin PJ, Vogelstein B, et al. Mutational analysis of the APC/ $\beta$ catenin/Tcf pathway in colorectal cancer. Cancer Res 1998;58:1130-4.

10 Miyaki $\mathbf{M}$, lijima T, Kimura J, et al. Frequent mutations of $\beta$-catenin and APC genes in primary colorectal tumors from patients with hereditary nonpolyposis colorectal cancer. Cancer Res 1999;59:4506-9.

11 Mirabelli-Primdahl L, Gryfe R, Kim H, et al. $\beta$-catenin mutations are specific for colorectal carcinomas with microsatellite instability but occur in endometrial carcinomas irrespective of mutator pathway. Cancer Res 1999;59:3346-51

12 Samowitz WS, Powers MD, Spiro LN, et al. $\beta$-catenin mutations are more frequent in small colorectal adenomas than in larger adenomas and invasive carcinomas. Cancer Res 1999:59:1442-4.

13 Akiyama Y, Nagasaki $\mathrm{H}$, Yagi KO, et al. $\beta$-catenin and adenomatous polyposis coli (APC) mutations in adenomas from hereditary non-polyposis colorectal cancer patients. Cancer Lett 2000;157:185-91.

14 Shitoh K, Furukawa T, Kojima M, et al. Frequent activation of the $\beta$-catenin-Tcf signalling pathway in nonfamilial colorectal carcinomas with microsatellite instability. Genes Chromosomes Cancer 2001;30:32-7.

15 Shimizu $Y$, Ikeda S, Fujimori $M$, et al. Frequent alterations in the Wnt signalling pathway in colorectal cancer with microsatellite instability. Genes Chromosomes Cancer 2002;33:73-81.

16 Kim IJ, Kang HC, Park JH, et al. Development and applications of a $\beta$-catenin oligonucleotide microarray: $\beta$-catenin mutations are dominantly found in the proximal colon cancers with microsatellite instability. Clin Cancer Res 2003:9:2920-5.

17 Rubinfeld B, Albert L, Porfiri E, et al. Binding of GSK-3 $\beta$ to the APC- $\beta$-catenin complex and regulation of complex assembly. Science 1996;272:1023-6.

18 Shalashor S, Kressbner U, Pahlman L, et al. Colorectal cancer with and without microsatellite instability involves different genes. Genes Chromosomes Cancer 1999;26:247-52.

19 UK Flexible Sigmoidoscopy Screening Trial Investigators. Single flexible sigmoidoscopy screening to prevent colorectal cancer: baseline findings of a UK multicentre randomised trail. Lancet 2002;359:1291-300.

20 Hoang JM, Cottu PH, Thuille B, et al. BAT-26, an indicator of the replication error phenotype in colorectal cancers and cell lines. Cancer Research 1997;57:300-3.

21 Zhou XP, Hoang JM, Li YJ, et al. Determination of the replication error phenotype in human tumors without the requirement for matching normal DNA by analysis of mononucleotide repeat microsatellites. Genes Chromosomes Cancer 1998;21:101-7.

22 Loukola A, Eklin K, Laiho $\mathrm{P}$, et al. Microsatellite marker analysis in screening for hereditary nonpolyposis colorectal cancer (HNPCC). Cancer Res $2001 ; 61: 4545-9$

23 Polakis P. Wnt signalling and cancer. Genes Dev 2000;14:1837-51

24 Young J, Leggett B, Gustafson C, et al. Genomic instability occurs in colorectal carcinomas but not in adenomas. Hum Mutat 1993:2:351-4.

25 Loukola A, Salovaara R, Kristo P, et al. Microsatellite instability in adenomas as a marker for hereditary nonpolyposis colorectal cancer. Am J Pathol 1999; 155: 1849-53.

26 lino H, Simms L, Young J, et al. DNA microsatellite instability and mismatch repair loss in adenomas presenting in hereditary non-polyposis colorectal cancer. Gut 2000;47:37-42

27 Pedroni M, Sala E, Scarselli A, et al. Microsatellite instability and mismatchrepair protein expression in hereditary and sporadic colorectal carcinogenesis. Cancer Res 2001;61:896-9. 